\title{
La cabeza de piedra de manatí: Historia de una pieza arqueológica
}

\author{
Bernardo Ceferino Vargas
}

Este estudio trata de identificar y documentar la historia de una pieza arqueológica: la piedra con cabeza de manatí, localizada en el municipio de Laguna de Perlas, RAAS, específicamente, en la comunidad miskita de Kahkabila. La existencia de esta piedra antecede a la llegada de los ingleses o de los españoles. Según los portadores de la comunidad, esta pieza arqueológica jugó un rol importante en la cosmovisión de los miskitos del lugar, que la han considerado como la "cabeza de piedra del pez madre de manatí" (palpa en miskito). Según los portadores culturales consultados, nadie sabe cómo llegó la pieza a la cuenca de la Loma Roja o Loma de Vaca $^{1}$ (Yangki Hill), pero, la verdad es que los indígenas la encontraron entre las raíces de un árbol de chilamate desde donde, según dicen, jugó un importantísimo papel en la caza de manatíes.

\section{EI manatí y su relación con los indígenas de Kahkabila}

Los meses de mayo, junio y julio comienza a crecer el alimento preferido de los manatíes (algas, hierbas verdes y lama) en la cuenca de la Loma de Vaca Era la temporada cuando se movilizaban los manatíes en busca de alimento y refugio en dicha cuenca. Para los indígenas de esos tiempos, cuando la cabeza de piedra de manatí se movía o cambiaba de posición, el día siguiente era momento oportuno en que debían salir a cazar manatíes. Entonces se preparaban para la caza, con todos sus instrumentos: arpón, flechas, mecates y cuchillos. Los comunitarios, cuando se dan cuenta que la cabeza de piedra se había movido de su posición se alegraban grandemente, porque, al día siguiente, cada uno cazaba de tres a cinco manatíes y la comunidad iba no sólo a comer la exquisita carne del manatí, la cual tiene distintos y deliciosos sabores, sino que también conseguirían aceite para cocinar y medicina para curar granos en la piel y el reumatismo. Cuando la piedra giraba su cabeza hacia el sureste, significaba que los manatíes iban saliendo ya de la bahía, buscando los grandes ríos (Patch, Niary Wawashang, Smaya, Suaka, Ibu, Lagoon y Taplak),

\section{Importancia de la piedra con cabeza de manatí}

Debido a estos atributos de la piedra, según los portadores y portadoras culturales, los indígenas de esos tiempos tenían cercada con palos rollizos la Loma de Vaca, para proteger la cabeza de piedra de manatí. Es importante señalar que en esta loma se han encontrado restos de piezas arqueológicas.

Hasta la fecha no saben cuál fue la causa por la cual esta pieza histórica quedó inmovilizada, puesto que hasta los más viejos portadores afirman no haberla visto moverse nunca, pero los indígenas creen que la razón de su inmovilidad actual se debió a que alguna mujer en período menstrual tocó la cabeza de la piedra, lo cual debilitó el movimiento de rotación de esta pieza arqueológica de la cual muchos comunitarios creen que fue creación del mismo Jesucristo.

Los portadores culturales consultados fueron: Kelaina Elia Schwartz, Juana Bonilla Theodore, Raymundo López Joseph, Sharly Humphrys Moses, Lauterio Thomas Fox, Jaime Suarez Moses, Edgar Theodore Shawartz y Oscar Theodore Shawartz.

\footnotetext{
El manatí es un mamífero acuático al que también se le llama vaca marina, por sus dimensiones y semejanza con este mamífero.
} 


\section{BIBLIOGRAFIA}

Balladares, S. N. y Lechado, L. (2009). El inventario de sitios arqueológicos en Nicaragua: Una metodología participativa. Managua: UNAN.

Cunningham Kain, M. \& Mairena Arauz, D. (coords.). (2009). Guía metodológica para la elaboración de línea de base para el programa de revitalización cultural y desarrollo productivo. Documento inédito. UNESCO.

Fernández, Ma. I. (2007). ¿Puede ser la mística una terapia para las religiones?. Anuario de Estudios Místicos, (4), $18-28$.

Galezzi Alvarado, J. (1972). Definición y utilidad de la historia. En Historia universal. UNAM. Recuperado el 27 de marzo del 2012, en http://www.buenastareas.com/ensayos/Resumen-Historia-Universal/216457.html

Incer Barquero, J. (1985). Toponimias indígenas de Nicaragua. San José, C.R.: Libro Libre.

Losada Goya, J. M. (2008). Mito moderno y proceso de mitificación. Madrid: Universidad Complutense.

Montoya, K. (2008). Trichechusmanatus manatí del Caribe, manatí de la Costa, vaca marina. Revista Biodiversidad. Recuperado el 27 de marzo del 2012, de http://scarebeta.blogspot.com/search?updated-min=2008-01-01

Nicaragua. Asamblea Nacional Constituyente. (2009). Principios fundamentales, título I, cap. único, arto. 5, párrafo 3. En la Constitución política de la república de Nicaragua (p. 9). (3ª ed.). Managua: HISPAMER.

Nicaragua. Asamblea Nacional. Ley No. 28, Estatuto de la autonomía de las regiones de la Costa Atlántica de Nicaragua. (1987, 30 de octubre). La Gaceta, (238). cap. 2, arto. 8, párrafo 5, p. 2835.

Poveda Álvarez, L. J. y Sánchez, V. (1999 ). Claves dendrológicas para la identificación de los principales árboles y palmas de la Región Norte y Atlántica de Costa Rica. San José, C.R.: Guayacán.

Organización de las Naciones Unidas para la Educación, la Ciencia y la Cultura. (2002). Glosario sobre patrimonio cultural inmaterial. Recuperado el 28 de febrero del 2012, de http://www.unesco.org

Organización de las Naciones Unidas para la Educación, la Ciencia y la Cultura. (2009). Informe línea de base para el programa de revitalización cultural y desarrollo productivo creativo en la Costa Caribe de Nicaragua. UNESCO. Recuperado el 28 de febrero del 2012, de (http://www.undp.org.ni/files/contrataciones/1243441413 TDR Facilitador_Bilwi[1].pdf

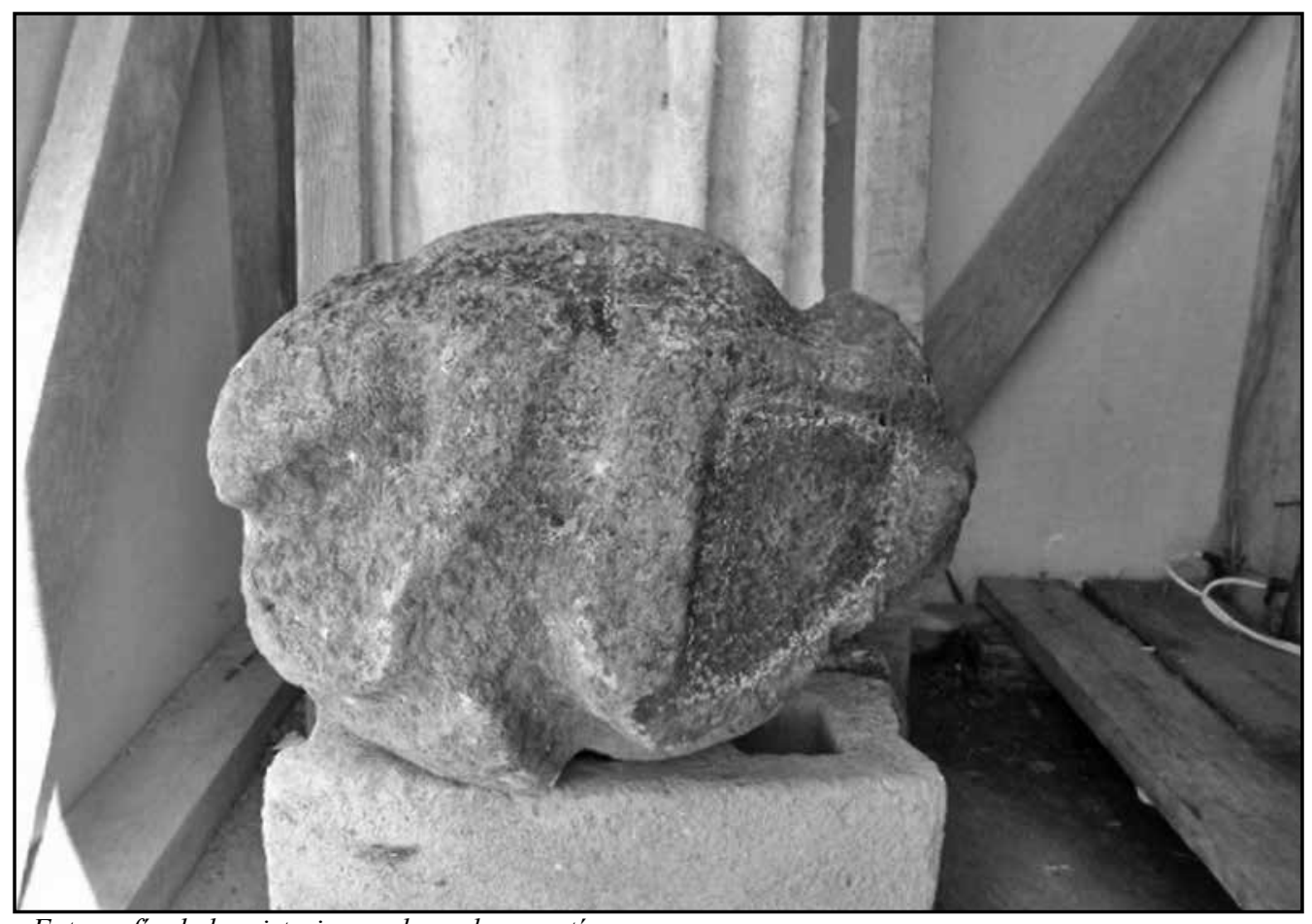

Fotografia de la misteriosa cabeza de manatí. 